
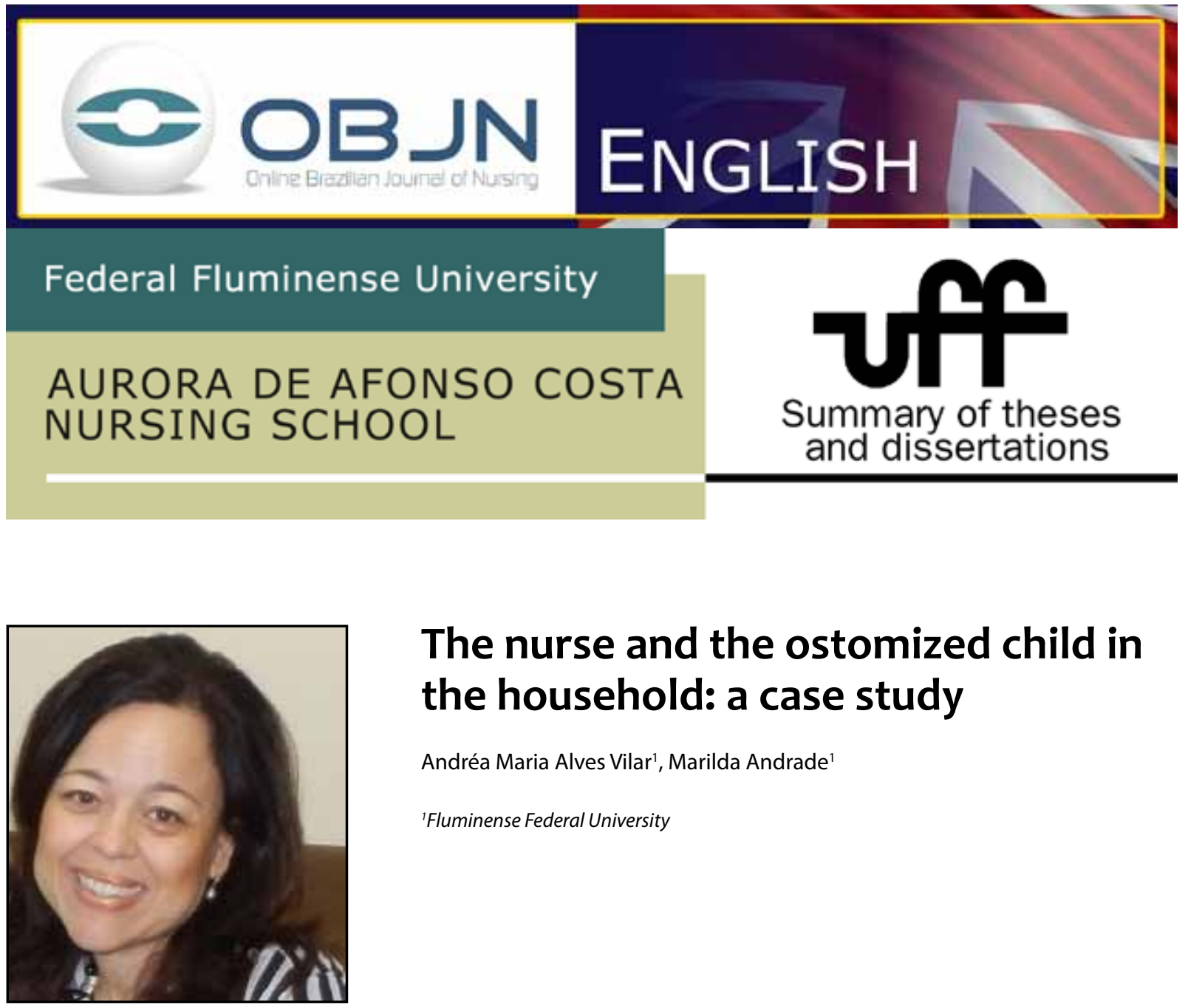

\title{
The nurse and the ostomized child in the household: a case study
}

Andréa Maria Alves Vilar' ${ }^{1}$ Marilda Andrade

'Fluminense Federal University

\section{ABSTRACT}

Aim: To describe how nurses are working in their daily practices with caregivers/families of children with stomata with respect to self-care and procedures for hospital discharge; to identify when nurses begin the guidance for hospital discharge to the caregiver/family of the child with a stoma; to discuss how the family involvement is constituted in the care of children with stoma from admission until discharge, from the perspective of the nurse.

Methods: This is a descriptive case study in which we used a qualitative approach. The study was conducted with 31 nurses of the Neonatal Intensive Care Unit of a University Hospital in the city of Rio de Janeiro.

Results: nurses guide families regarding the hospital discharge of stomized children (58\%) and start with the guidance as soon as they have an indication of the development of the stoma (58\%).

Discussion: The orientation minimizes the difficulties presented by the caregiver.

Descriptors: Nursing; Technology; Child; Surgical Stomas. 


\section{INTRODUCTION}

Currently, the assistance for newborns and children has been improving due to the high level of technology used in Intensive Care Units (ICU). As a result of these advancements we have a higher survival rate for the premature clientele of Neonatal Intensive Care Units $(\mathrm{NICU})^{(1)}$. Many of these end up in hospital as Children with Disabilities (CWD) which, for Holster ${ }^{(2)}$, are those who have chronic illnesses, physical disabilities and developmental disorders. In this context, many children present stoma, which is a word that derives from the Greek and means mouth ${ }^{(3)}$. The presence of the family, reinforced by the Statute for Children and Adolescents (SCA), along with the child in the hospital setting, involves their interaction in the healthcare process, which will be essential in the home environment. It is up to the nurse, not only to have the ability to deal with this technology, but also to create a supporting framework for the guidance and health education of the caregiver/family member, providing him or her with a degree of independence regarding care within and outside the hospital.

\section{AIMS}

To describe how nurses work in their daily practices with caregivers/family members of children with stoma with respect to self-care and care for hospital discharge;

To identify when nurses begin to guide caregivers/family members of children with stoma for hospital discharge;

To discuss how the family can participate in the care of children with stoma from hospital admission through to discharge from the perspective of the nurse;
To propose the elaboration of a nursing assessment instrument for the hospital discharge of children with stoma.

\section{METHOD}

The strategy used was a case study associated with a descriptive study, in which a qualitative approach was used. The study was conducted in the NICU of a University Hospital located in the north of Rio de Janeiro. This sector consists of 21 beds ( 13 intensive-care beds and eight beds for intermediate nursery) and a drug-preparation room. The survey was conducted with 31 nurses on duty in the various sectors of the NICU, comprising the Day Service (DS) and the Night Service (NS). Data collection occurred by means of a semi-structured interview script. This was done at random in the period from January to March 2012, until the occurrence of repeated information regarding the topic covered emerged. The instrument used was composed of 13 questions. Questions 1-8 are intended to create a socio-demographic profile, and questions 9-13 are specific questions focused on the role and perception of professionals on the topic of stoma. The analysis of data was done through the content analysis technique, in the form of thematic analysis according to Bardin.

\section{RESULTS}

From the analysis, three categories and six subcategories emerged: 1 - Experience of the respondents with stomized newborns and children; 2 - Restrictive factors for nurses in the relationship with the caregiver concerning the subcategories: 2.1 - sector scale, 2.2 - characterization of the stoma, which defines the behavior of the nurse, 2.3 - learning process; 3 - The importance of the family regarding the 
ostomized newborn and child, concerning the subcategories: 3.1 - preparation for discharge: professional-family relations 3.2 - the difficulty of having a disabled child, 3.3 - the main caregiver, "the mother"; 4 -The beginning of the guidance to families/caregivers.

It was found that nurses know the term stoma $(90.32 \%)$, but $74.19 \%$ are limited to intestinal stomas; they guide families for hospital discharge of stomized children (58.06\%) and initiate the orientations as soon as they have an awareness of the presence of the stoma (58\%).

\section{DISCUSSION}

The nurse works in the guidance process leading to hospital discharge, but each one chooses the ideal time for this care. Some believe that the best time is during the daily care provided to the child, while others believe that the guidance should be established nearer the hospital discharge as ordered by the physician. Thus, they find themselves in this daily care gap, since there is systematization and individualization of care based on the needs of each child and his/her family, in addition to a multidisciplinary scientific basis.

\section{CONCLUSION}

The systematized participation not only of nurses, but of the multidisciplinary team, is essential in terms of the orientation for hospital discharge with regard to the ostomized child caregiver.

\section{REFERENCES}

1. Itabashi K, Horiuchi T, Kusuda S, Kabe k, Itani y, Nakamura T, et al. Mortality rates for extremely low birth weight infants born in Japan, 2005. Pediatrics. 2009; 123 (2): 445-50.

2. Hostler, SL. Family-centered care. Pediatr Clin North Am. 1991; 38(6):1545-60.

3. Colorretal [homepage in the internet]. Definições e Técnicas de Estomas Intestinais [cited 2013 June 25]. Available from: http://www.colorretal.com. br/index.php/2011/04/15/definicoes-e-tecnicas-de-estomas-intestinais-parte-1/

Place and Defense Date: Niterói, Brazil, in January 04, 2013.

Examiners: Prof. Dr. Marilda Andrade (Advisor); Prof. Dr. Dalvani Marques (President of the Examining Board); Prof. Dr. Angelina Maria Aparecida Alves (Examining Member); Prof. Dr. Rosane Cordeiro Burla de Aguiar (Examining Member).

Reference: Vilar, AMA. O enfermeiro e o cuidar da criança portadora de estoma: um preparo para o domicílio. Rio de Janeiro. Dissertação (Mestrado de Enfermagem) - Universidade Federal Fluminense; 2013.

Received: $31 / 07 / 2013$

Revised: 05/08/2013

Approved: 10/08/2013 